\title{
Plasma progesterone concentration during oestrus cycle and pregnancy in Finnsheep and other prolific sheep breeds
}

\author{
B. REKLEWSKA, Z. J. TYSZKA and R. NIŻNIKOWSKI \\ Warsaw Agricultural University \\ ul. Przejazd 4, 05-840 Brwinów, POLAND
}

\begin{abstract}
The aim of the study was to evaluate the relationship between the litter size and plasma progesterone (PP) concentration during the breeding season and pregnancy in some prolific sheep breeds. Investigations were performed during two consecutive reproductive cycles. PP concentrations were determined in Finnsheep $(n=16)$, Polish Heath $(n=13)$, Friesian $(\mathrm{n}=10)$, Zelazna $(\mathrm{n}=12)$ and Karakul $(\mathrm{n}=14)$. Prolificacy was $3.14,2.0,2.0,1.8$ and 1.12 , resp. Highly significant differences in PP levels during pregnancy were found between the prolific breeds and breed with the lowest litter size. There was also a significant effect of pregnancy stage on the PP concentration. Breed differences in PP levels during the oestrus cycle were the most pronounced on the 10th day of the cycle. However, due to a considerable variation within breeds they were statistically insignificant.
\end{abstract}

Index words: Finnsheep, Polish Heath, Karakul, Friesian, Zelazna, prolificacy, plasma progesterone

\section{Introduction}

Among different attempts of analysing the variation in the ovarian activity, Wheeler and Land (4) contributed to the accumulated knowledge with their investigations concerning genetic variation in the ovulation rate and its relation to the luteal function, while others tried to find out differences in plasma progesterone (PP) levels during pregnancy between ewes carrying single or twin foetuses (1, 2). However, it is still not clear whether there is a possibility to predict the litter size (LS) on the basis of PP concentration either dur- ing oestrus cycle or during pregnancy. Thus, the aim of the present study was to evaluate the relationship between the LS and the PP during oestrus cycle and pregnancy.

\section{Material and methods}

Investigations were performed at Zelazna Experimental Farm of Warsaw Agricultural University during two consecutive breeding seasons. All the animals were kept in the same flock. PP concentration was determined using the direct RIA method (3). Blood samples 
were taken by jugular veni puncture on every second day of the oestrus cycle and at approximately 3 weeks intervals during pregnancy in Finnsheep $(\mathrm{F}, \mathrm{n}=16)$, Polish Heath $(\mathrm{n}=13)$, Friesian $(\mathrm{n}=10)$, Zelazna $(\mathrm{n}=12)$ and Karakul $(\mathrm{K})$ called also Astrakhan $(\mathrm{n}=14)$. Results of the investigations were analysed by least-squares analysis of variance. The model included main effects of season, breed, day of the cycle, stage of pregnancy and LS versus PP concentrations.

\section{Results and discussion}

PP concentrations during oestrus cycle are presented in table 1. The examined breeds varied in their respective PP levels. The breed differences were most clearly pronounced on 10th day of the cycle, with $\mathrm{F}$ having the highest and $\mathrm{K}$ the lowest PP concentration. Thus, the results obtained in this work support the observations of WHEELER and LAND (4) that the circulating PP concentration in the middle of the luteal phase is related to the ovulation rate. However, due to a large within breed variation the differences in PP levels during oestrus cycle between breeds were not significant.

PP concentrations during pregnancy in relation to LS are demonstrated in table 2. It can be noted, that the presented PP levels changed significantly depending on the stage of pregnancy. A similar variation on PP concentration during pregnancy was described by BASSET et al. (1). There were also significant differences in the PP levels depending on LS. At all the examined stages of pregnancy the lowest PP concentrations were found in ewes carrying single foetuses, while the highest ones in ewes carrying triplets.

It should be mentioned that the PP concentrations in ewes carrying quadruplets were "out of range", i.e. lower than those found in ewes with triplets. However, the number of dams with quadruplets $(\mathrm{n}=2)$ was too small for drawing any conclusions. The available informations concerning the relationship between on PP levels during pregnancy and LS

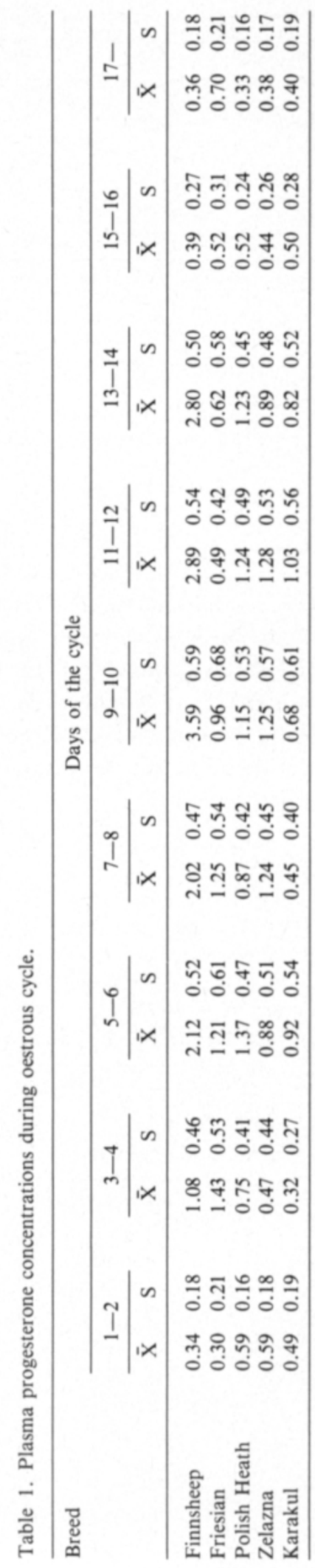


Table 2. Average plasma progesterone concentrations in relation to the litter size and the pregnancy stage.

\begin{tabular}{llllllll}
\hline Litter size & \multicolumn{7}{c}{ Days of pregnancy } \\
\cline { 2 - 6 } & $1-25$ & $26-50$ & $51-75$ & $76-100$ & $101-125$ & $126-$ & Mean \\
\hline Singles & 2.70 & 3.33 & 3.85 & 3.30 & 1.81 & 5.26 & $2.52^{\mathrm{BCD}}$ \\
Twins & 3.82 & 4.16 & 4.78 & 4.28 & 2.64 & 6.39 & $2.85^{\mathrm{AC}}$ \\
Triplets & 4.98 & 5.87 & 8.17 & 4.97 & 3.41 & 7.88 & $3.29^{\mathrm{AB}}$ \\
Quadruplets & 2.95 & 2.28 & 1.43 & 3.37 & 2.53 & 3.46 & $3.07^{\mathrm{A}}$ \\
Average & $2.61^{\text {bCDF }}$ & $2.91^{\text {aEF }}$ & $2.92^{\text {aEF }}$ & $3.04^{\mathrm{AEF}}$ & $2.40^{\mathrm{BCDF}}$ & $3.73^{\mathrm{ABCDE}}$ & \\
\hline
\end{tabular}

a, b, c, d, e, f $P \leq 0.05$

A, B, C, D, E, F P $\leq 0.01$

are limited to the comparisons of single and twin pregnancies.

\section{Conclusions}

1. In general, results of these investigations confirm the earlier findings concerning the possibility of predicting LS on the basis of PP levels during pregnancy.

2. Significant changes in the PP concentrations during pregnancy may influence the

\section{References}

1. Basset, J.M., Oxborrow, T.J., Smith, I.D. \& Thor. BURN, G.T. 1969. J. Endocr. 45: 449-457.

2. Shemesh, M., Ayalon, N. \& Lindner, H.R. 1973. J. of Anim. Sci. 36: 726-729.

3. Кокот, F. \& Stupnickı, R. 1979. Metody radioim- results of prediction. Thus, the stage of pregnancy should be taken into account.

3. It is suggested, that the relationship between LS and PP level exists for LS within the range from singles to triplets. However, the number of the quadruplets was too small for drawing any conclusions.

4. The most pronounced breed differences in PP concentration during oestrus cycle were found in the middle of the luteal phase, but they were statistically insignificant. munologiczne i radiokompetycyjne stosowane w klinice. PZWL.

4. Wheeler, A.G. \& Land, R.B. 1977. Anim. Prod. 24: $363-376$. 